\title{
Reform, revolution and disruption in mental health care: a consumer's perspective
}

\author{
Jackie Crowe $e^{a, b}$
}

a National Mental Health Commission, Sydney, NSW, Australia

bCorresponding author: jackie.crowe.jackie@gmail.com

\section{Article history}

Publication date: April 2017

Citation: Crowe J. Reform, revolution and disruption in mental health care: a consumer's perspective. Public Health Res Pract. 2017;27(2):e2721711. doi: http://dx.doi.org/10.17061/phrp2721711

\section{Key points}

- Consumers of mental health care services are demanding an open, transparent and seamless system of care and support

- The rise of digital technologies has given consumers greater access to information, a new means for collaboration, and a more powerful voice to speak about their experiences with service provision, recovery and system failure

- Australia's mental health sector is nearing a tipping point for transformation

\section{Abstract}

Mental health leaders, policy makers and successive national and state governments have tried countless incremental reforms. Yet, for decades in Australia, independent inquiries and reports have concluded that our mental health 'system of care' is a misnomer. It is fragmented, ineffective, inefficient and unfair. For far too long, people, families and communities have paid a heavy price for this. Reform in itself will not be the solution that we can hang all our hopes on. Disruptive innovations are now sneaking into the mental health sector and beginning to be taken up en masse. Sitting alongside this is a budding revolution - an unrest stirring in our communities that has not been seen before in the history of mental health. People are raising their expectations and communities are demanding better. With external (revolution, disruption) and internal (reform) forces colliding at a similar time, a perfect storm is being created for what could be the long-awaited and much-needed change we have longed to see. But it will not be without pain because, given a choice, most will opt for stability over change. But ignoring what is coming may not be wise.

\section{Introduction}

Despite the work of well-intentioned providers, organisations and government entities, our fragmented mental health 'system of care' is struggling with increasing costs, uneven quality, human rights issues, rising suicide rates and people who are unable to live a full, contributing life of their choosing. ${ }^{1,2}$

Mental health leaders, policy makers and successive governments have tried countless incremental reforms - writing legislation, generating practice guidelines, producing national mental health standards, monitoring data, making patients better 'consumers's, improving access to care while containing costs, implementing electronic medical records - but collectively, for all the effort, time and dollars spent, there has been little impact in terms of outcomes for people, families and communities. ${ }^{4}$

A very long time ago, a person described to me his journey from mental ill health to mental health: "Too many years lost, too much suffering, too many shut doors."

He shared his pain and despair of recovering in a mental health system that was beyond broken and organised around clinician/service/organisation/ government need. Throughout the years, his words have echoed over and 
over again in the stories of far too many people who have spoken of their heartbreaking experiences to me and in many national inquiries, dating back to the Burdekin Report in 1993. ${ }^{5}$

The progression of Australian governments has made significant policy, funding and legislative commitments in the effort to reform the mental health system, or parts of it. The intent was not access to poor care; the objective was not inadequate quality; the pursuit was not to deliver bad results or be misaligned with the interests of consumers and families. Yet the reality is that many historical and recent Australian independent inquiries into mental health have agreed: reform efforts have not made the transformations we should be seeing, nor are they giving people the outcomes we should be expecting. . $^{6-9}$

Given the entrenched interests and practices of many decades, expecting mental health transformation that only comes from within (reform) is unrealistic.

\section{Partnerships advance revolution in mental health care}

To describe Australia's mental health care sector as a 'system' would be incorrect. We have a whole set of silos in health and mental health that barely connect. ${ }^{10}$ Rhetoric around better integration has remained a focal point since the 1992 National Mental Health Policy. The silo mindset did not appear accidentally and does not maintain itself. Successive government funding models have supported it $^{11,12}$, along with entrenched systemic cultural issues of providers, organisations and government entities. Many are wedded to old ways of doing business and are far too comfortable with the construct of silos to want to change. ${ }^{13}$

Consumers need to be savvy to make sure their needs are met in Australia's three-tiered system of healthcare. ${ }^{14}$ Coordinating care and navigating services can often become the domain of the consumer and their family. This is at a time when a person is unwell and may have multiple health, psychological or social needs, or be contemplating suicide, while their families are desperately worried.

Advocates from all parts of the mental health sector, tired of mental health 'reform' too often amounting to no more than 'rearranging the deck chairs on the Titanic', have been publicly critical of the system of care for decades. But advocacy from one sector alone will not change the status quo.

In recent times, a noticeable unrest has been stirring within our communities: a budding revolution. People, advocates and communities are expecting more. They are demanding an open, transparent and seamless system of care and support. ${ }^{9}$

Where once mental illness was talked about in hushed tones and suicide never mentioned, now consumers, families and communities are speaking out about their experiences with service provision, recovery and system failure to their communities and the world. They are aided by the evolution of social media and mobile technology.

The internet is the largest increase in human expressive capability in history, and it is turning advocacy as we know it on its head. The proliferation of digital channels and devices gives people greater access to information, and the means for communication and collaboration. This increasingly networked society is a petri dish for engagement, connections and partnership advances, and a revolution in mental health care.

\section{Rapid improvement in any field requires measuring results}

Measuring service activity provides little information about the consumer and family outcomes that are being achieved and the cost of that care. Advocates (especially consumers) have long emphasised and demanded a move from system inputs and outputs, and process measurement, to quality outcome measurements. To their disappointment, 'quality outcome measurement' has gravitated to the most easily measured and least controversial indicators. ${ }^{15}$

The true measures of quality are the outcomes that matter to the people who use (or will use) the service and their families. This requires a range of measures of consumer and family experience of care that are fit for purpose, and consumer self-rated measures. These measures exist in abundance, and are conveniently and widely available on the internet. The tragedy is the longstanding indifference to collecting and publicly reporting on outcomes. When outcomes are collected and reported publicly, providers, organisations and governments face both tremendous pressure and strong incentives to improve.

It is an uncomfortable truth that governments and private providers have continued to invest in reforming poorly performing information technology systems that are cumbersome and do not talk easily to each other (if at all). A new strategy is needed that incorporates networks of connectivity into all national and jurisdictional data infrastructure, and a new, more effective model where transparent, open-access, data are the default. Noting the utmost importance of protecting privacy and confidentiality, infrastructures that will act to both disseminate data and protect confidentiality are crucial.

\section{Waiting to be invited to participate? The game has been disrupted}

Consumer and family participation has been the foundation of all reform activities for decades. Although these have never been sustainably funded or supported, Australia can demonstrate some achievement in this 
space (with a big 'but' attached). However, participation as we once knew it is now not equipped to meet the changing landscape.

Once it could take weeks, at the discretion of the provider, to get a response about a complaint. Now a strategic social media post can have the same service contacting consumers within hours to enquire about their experience. Social media has disrupted the way service providers handle complaints. In a similar way, blogs, social media and personal web pages are beginning to disrupt the way we think about how people can participate in service planning and improvement.

Providers, organisations and governments would be wise to take heed. Forgetting to ask consumers and families to take part in key activities can now result in a social media feed reminding the organisation of "nothing about us without us". People are becoming increasingly active about posting their thoughts, ideas and needs. The challenge for providers, organisations and governments is how to face the implications of digital change, particularly the loss of control over the consumer relationship. However, few realise how fast the change needs to happen, or how transformational it needs to be.

Increasing consumer, family and community involvement in all processes and at all levels will become the number one objective for services and organisations if they want to stay relevant and competitive in a changing market, where new technologies and digital tools are empowering people at a pace not seen before.

\section{The end of business as usual}

The pace of technological change is increasing exponentially. Digital services have become universal and changed every aspect of how we live our lives. Society is becoming increasingly familiar and comfortable with using technology for a wide range of transactions, including how we manage our physical and mental health.

Our smartphones can now know more about our physical and mental health and wellbeing than our primary healthcare provider or specialist. Both an imperative and a challenge for healthcare providers will be how to innovate and engage with the consumer and their family who are using digital health technologies for improved consumer outcomes. Unfortunately, solutions often focus on the risks of people using health technology or reinventing the wheel, rather than building robust platforms, infrastructure and shared services that complete the circle of care. Digital mental health must be seen much more as an opportunity to be tapped than as a risk to guard against.

Technologies that have thrived, from electricity through to the digital age, have grown, not because they deliver more, but because they deliver better.

\section{Unification of reform, revolution and disruption}

In industry, disruptive innovation sneaks in from below. In community, revolution starts with a few committed people and grows to a tipping point. System reform is built on past foundations. While providers focus on their services or products, their research, their education or training, their processes and procedures, and fitting people into their type of service, they can fail to see that the average consumer and their family does not want or like what is on offer. They miss the signs of disruption and revolution, and dismiss and resist reform in an effort to preserve their traditional market hegemony.

Given a choice, most of us will opt for stability over change. ${ }^{16}$ Ignoring what is coming may not be wise - for the times, they have changed.

\section{Competing interests}

None declared

\section{Author contributions}

$\mathrm{JC}$ is the sole author.

\section{References}

1. Stange KC. The problem of fragmentation and the need for integrative solutions. Ann Fam Med. 2009;7(2):100-3.

2. Griffiths M, Mendoza J, Carron-Arthur B. Whereto mental health reform in Australia: is anyone listening to our independent auditors? Med J Aust. 2015;202(4):172-4.

3. Mold A. Making British patients into consumers. Lancet. 2015;385(9975):1286-7.

4. Medibank Private Limited and Nous Group. The case for mental health reform in Australia: a review of expenditure and system design. Melbourne: Medibank Private Limited and Nous Group; 2013 [cited 2017 Mar 9]. Available from: www.medibank.com.au/Client/Documents/Pdfs/ The_Case_for_Mental_Health_Reform_in_Australia.pdf

5. Burdekin B. Report of the national inquiry into the human rights of people with mental illness. Sydney: Australian Human Rights Commission; 1993 [cited 2017 Mar 22]. Available from: www.humanrights.gov.au/publications/ report-national-inquiry-human-rights-people-mentalillness

6. Groom G, Hickie I, Davenport T. 'Out of hospital, out of mind!' A report detailing mental health services in Australia in 2002 and community priorities for national mental health policy for 2003-2008. Canberra: Mental Health Council of Australia; 2003 [cited 2017 Mar 9]. Available from: mhaustralia.org/sites/default/files/ imported/component/rsfiles/mental-health-services/Out_ of_Hospital_Out_of_Mind.pdf 
7. Mental Health Council of Australia. Not for service: experiences of injustice and despair in mental health care in Australia. Canberra: Mental Health Council of Australia; 2005 [cited 2017 Mar 9]. Available from: www.humanrights.gov.au/sites/default/files/content/ disability_rights/notforservice/documents/NFS_Finaldoc. pdf

8. The Senate Select Committee on Mental Health. A national approach to mental health: from crisis to community. Canberra: Commonwealth of Australia; 2006 [cited 2017 Mar 9]. Available from: www.aph.gov.au/ Parliamentary_Business/Committees/Senate/Former_ Committees/mentalhealth/report/index

9. National Mental Health Commission. Contributing lives, thriving communities: report of the national review of mental health programmes and services. Sydney: NMHC; 2014 [cited 2017 Mar 9]. Available from: www. mentalhealthcommission.gov.au/our-reports/contributinglives,-thriving-communities-review-of-mental-healthprogrammes-and-services.aspx

10. National Health and Hospitals Reform Commission. A healthier future for all Australians: final report June 2009. Canberra: Commonwealth of Australia; 2009 [cited 2017 Mar 17]. Available from: webarchive.nla.gov.au/ gov/20140211213250/http://www.yourhealth.gov.au/ internet/yourhealth/publishing.nsf/Content/nhhrc-reporttoc
11. Oliver-Baxter J, Brown L. PHCRIS research roundup: primary health care funding models. Adelaide: Primary Health Care Research and Information Service. Available from: www.phcris.org.au/phplib/filedownload.php?file=/ elib/lib/downloaded_files/publications/pdfs/phcris_ pub_8412.pdf

12. Whitford H, Buckingham B, Manderscheid R. Australia's national mental health strategy. Br J Psychiatry. 2002;180(3):210-15.

13. Institute of Medicine (US) and National Academy of Engineering (US) Roundtable on Value \& Science-Driven Health Care. Engineering a learning healthcare system: a look at the future: workshop summary. Washington, DC: National Academies Press (US); 2011. Chapter 3, Healthcare system complexities, impediments, and failures; p. 117-70.

14. Health Issues Centre: consumer voices for better healthcare. Melbourne: Health Issues Centre. Understanding our health care system; [cited 2017 Mar 3]; [about 2 screens]. Available from: healthissuescentre.org.au/consumers/health-care-inaustralia/understanding-our-health-care-system/

15. Rosenberg S, Hickie I, McGorry P, Salvador-Carulla L, Burns J, Christensen $\mathrm{H}$, et al. Using accountability for mental health to drive reform. Med J Aust. 2015;203(8):328-30.

16. Eidelman S, Crandall C. The intuitive traditionalist: how biases for existence and longevity promote the status quo. Adv Exp Soc Psychol. 2014;50:53-104.

\section{Copyright: (c) (1) (2)}

(C) 2017 Crowe. This article is licensed under the Creative Commons Attribution-NonCommercial-ShareAlike 4.0 International Licence, which allows others to redistribute, adapt and share this work non-commercially provided they attribute the work and any adapted version of it is distributed under the same Creative Commons licence terms. See: www.creativecommons.org/licenses/by-nc-sa/4.0/ 